\title{
VOLUNTARY PARTICIPATION IN REHABILITATION: LESSONS LEARNED FROM A CLUBHOUSE ENVIRONMENT
}

\author{
JEANNETTE WAEGEMAKERS SCHIFF, HEATHER COLEMAN, \\ and DEEANA MINER \\ Faculty of Social Work, University of Calgary
}

\begin{abstract}
Clubhouses, as voluntary communities, can be excellent indicators of recovery environments for persons who have a mental illness. To understand why people become affiliated with a Clubhouse and others disengage, 4 focus groups with Clubhouse members and 1 with staff explored questions of membership retention. Responses encompassed 4 domains: personal, interpersonal, structure, and organizational environment. These domains were interwoven with values of acceptance without stigma, empowerment, self-determination, egalitarian relationships, independence, interdependence, dignity, respect, hope, and positive expectations. The domains and values correspond to elements that aid recovery. The presence and absence of such domains encouraged people to either attend or stay away from the organization. Overall analyses of the groups' responses suggest that recovery-oriented values and organizational climate are important factors in determining attendance in a consumer-oriented program.
\end{abstract}

Clubhouses and drop-in centres distinguish themselves from other services in the mental health system by their voluntary nature. People choose to attend because of some intrinsic value derived from this environment rather than because it will result in receiving or being eligible for clinical services or other entitlements such as income or housing. In this study we were interested in understanding the organizational characteristics of a Clubhouse environment that would promote member attendance or result in disengagement.

Persons recovering from mental illness have an increasing presence in the development of treatment and rehabilitation environments conducive to recovery (Resnick, Rosenheck, \& Lehman, 2004). Their participation is resulting in a demand for a radically different approach to services and service systems for those who have experienced severe mental illness (Everett et al., 2003), one that relies on non-coercive engagement of service providers and recipients. People in recovery have historically been prescribed treatment and rehabilitation programs, despite lack of empirical evidence, while little effort has been made to ascertain acceptable and helpful interventions.

Two forces have altered rehabilitation approaches: the consumer movement that demands a participatory role in shaping service delivery, and the recovery movement which insists that professionals and the public recognize that mental illness is not a sentence to life-long profound disability. Both 
movements raised awareness of the importance of acceptable therapeutic approaches within a recoveryoriented climate. When people actively participate in rehabilitation programs that are neither clinical nor required for supportive entitlements, the question of what constitutes an acceptable environmentthat is, what leads consumers to speak through their feet, to choose whether or not to come-takes on a new prominence.

Clubhouse, a psychosocial rehabilitative program in existence for over 50 years, is found in industrialized countries (U.S., Canada, Sweden) and developing countries (Pakistan, Bosnia), and has a significant presence in six Canadian provinces (Alberta, British Columbia, Manitoba, Nova Scotia, Ontario, and Prince Edward Island). The International Centre for Clubhouse Development (ICCD) is the only international mental health organization to be conferred by the United Nations with "special consultative status," a status which indicates the organization's global acceptance. Clubhouses emphasize voluntary participation, egalitarian staff-member relationships, and absence of direct clinical services.

A Clubhouse is an intentional community comprising people who are experiencing a serious mental illness and staff who provide a basic operational structure (Beard, Propst, \& Malamud, 1982; Macias, Jackson, Schroeder, \& Wang, 1999). In order to reinforce the organization's self-definition as a club wherein membership entails specific rights, participants are called members (as opposed to patients, consumers, or clients). Clubhouses do not operate within a medical model focused on symptoms, diagnoses, and treatment; instead, they have a distinctive egalitarian milieu which is based on a humanistic recognition of the importance of each individual, the relationships that a person needs to grow and succeed, and the environment in which those relationships can be fostered. Specifically, members who require clinical services such as counselling or psychotropic medication receive them elsewhere. Further, the program cannot be used to secure housing or income entitlements. Thus, participation is most often because of the intrinsic characteristics of a Clubhouse environment and for no ulterior purposes.

In comparison to programs such as ACT (Assertive Community Treatment), research on the Clubhouse model has been scant and narrowly focused. Early studies included positive outcomes of membership: decreased hospitalization (Beard, Malamud, \& Rossman, 1978; Warner, Huxley, \& Berg, 1999); reduced treatment cost (Landis, 1999); and improved quality of life (Oliver, Huxley, Bridges, \& Mohamad, 1996). Member characteristics and fidelity to the program model have also been investigated (Donnell, 2001; Dorio, Guitar, Solheim, Dvorkin, \& Marine, 2002; Macias, Barriera, Alden, \& Boyd, 2001). A number of articles attest to the positive experiences of members and staff in Clubhouses (Angers, 1992; Aquilla, Santos, Malamud, \& McCorory, 1999; Glickman, 1992). These accounts capture international perspectives (Norman, 2006; Yau, Chan, Chan, \& Chui, 2005; Yildiz, Tural, Kurdo_lu, \& Emin Önder, 2003) and aspects of cultural sensitivity (Coolidge, Wright, \& DiSanto, 1995). The bulk of additional studies focus on employment outcomes, including characteristics and models of supported employment and job training (Bond, Drake, Becker, \& Mueser, 1999; Crowther, Marshall, Bond, \& Huxley, 2002; Dorio \& Marine, 2004; Leff et al., 2005; Macias, 2001; Macias, DeCarlo, Wang, Frey, \& Barreira, 2001).

Reference to the organizational characteristics of Clubhouses can be found in studies on Clubhouse functioning. Donnell (2001) mentions values such as recovery, choice, control, and a sense of 
VOLUNTARY PARTICIPATION IN REHABILITATION

community as integral to the Clubhouse philosophy. Boll (1995) identifies key factors which negatively influence program functioning, including lack of staff responsiveness to members, insufficient new member orientation, and inconsistent reach-out to non-attending members. Clubhouse environment and culture has recently been mentioned by some investigators (Donnell, 2001; Norman, 2006; Rosenfeld \& Neese-Todd, 1993). Despite the popularity of the Clubhouse model and the existence of a body of literature on the importance of organizational culture and climate on membership (Waegemakers Schiff, 2001), Clubhouse literature remains devoid of an examination of the organizational climate and specific program attributes which lead to member participation and retention.

Unlike most mental health programs that prescribe treatment methods, program activities, and attendance requirements, Clubhouses stipulate a voluntary membership—one which is neither mandated, used as a prerequisite for entitlements, nor contingent on factors such as attendance or participation in activities. We would, therefore, expect that members participate for self-directed reasons. Nonetheless, not all Clubhouse members continue their participation; indeed, most Clubhouses report an active membership of $40 \%$ to $45 \%$ of their total enrolement (Johnsen, McKay, Corcoran, \& Lidz, 2002). Accordingly, we expect that examining the factors that influence the decision to attend or to withdraw from participation in a Clubhouse may shed light on what components of a recovery environment are important for persons who have a serious mental illness. Articulation of recovery components can then act as an impetus for further replication of this and similar models. The present study, therefore, attempted to shed light on the interpersonal and organizational elements which encourage program engagement or disengagement within a Clubhouse milieu.

\section{METHODOLOGY}

Based on the premise that Clubhouse is a unique model of rehabilitative services that may reflect individual and organizational dynamics not found in other mental health programs, and because of a paucity of previous research on Clubhouse membership, we decided to explore these issues through focus groups. When a specific focus of research is not well understood, a grounded theory approach can help to uncover key aspects of the topic. Following investigative methods proposed by Glasser (1992), we used a qualitative approach involving focus groups of members and staff to identify these dynamics. Proponents of qualitative research and grounded theory caution that, in many instances, investigators have a priori assumptions about the theoretical aspects of their investigations (Belgrave, Zablotsky, \& Guadagno, 2002). Although a considerable body of literature exists on organizational behaviour and dynamics (including organizational culture), few focus on voluntary, participatory organizations. We recognized that our findings could either affirm existing theories or uncover alternative dynamics in organizations that have the unique participatory features of Clubhouses. This potential for discovering undocumented aspects of voluntary organizations led us to adopt a modified grounded theory approach.

Although Clubhouses have a long history, there has been no attempt to examine factors that contribute to member retention. To explore these dynamics, we conducted a series of focus groups with members and staff of an accredited Clubhouse. Fidelity to the original Clubhouse concept has received considerable attention (Boyd, 1997; Macias, Barriera et al., 2001), especially with respect to program 
outcomes. Because not all programs that self-identify as a Clubhouse are faithful to the model and we hoped to allow for some generalizability of our results, we chose to restrict our study to an accredited program.

\section{Participants}

Thirty-nine Clubhouse members and eight staff attended one of five focus groups. One of the major principles in Clubhouse organization is that all activities are equally open to staff and members and that no activity excludes either. For this research project to succeed, both groups needed a forum where there was minimal perceived influence to provide socially acceptable responses. Groups were therefore separated into member-only and staff-only to minimize perceived social pressure.

Members and staff were recruited through announcements at Clubhouse meetings and by notices on bulletin boards. We also purposefully recruited some participants to reflect: (a) a range of long-time and new members; (b) frequent, intermittent and past attendees; (c) a broad age range of participants; and (d) a gender balance. To consider views of inactive members, current members recruited five disengaged people (previous attendees). Focus group size was capped at 10 participants each and meeting times were determined by the Clubhouse membership. No identifying data were collected so that all results could be reported anonymously.

\section{Focus Group Interviews}

All focus groups were conducted at the Clubhouse and were led by a researcher experienced in group dynamics, Clubhouse philosophy, and focus group techniques. The study protocol was approved by the Conjoint Faculties Research Ethics Board at the University of Calgary.

Through previous work, we had established relationships with members and staff. Unlike focus groups where the researchers are relatively unknown to participants, these groups began with high levels of familiarity and trust. Group interaction and cohesion rapidly emerged and the dialogue was open and specific. Familiarity with the participants also facilitated our ability to elicit responses from more silent members and to probe for clarification. This enriched the range of responses and assured that individual voices were heard.

Groups met for 90 minutes each and discussed two general questions: (a) What factors influence a person's decision to join and remain at the Clubhouse; and (b) What influences a person's decision to withdraw from Clubhouse involvement? As each question was explored, participants were encouraged to answer from several perspectives (their personal experiences, their personal opinions, the reports and opinions that they have heard from other members) and to include both positive and negative impacts. We encouraged participants to provide concrete examples that supported and provided greater specificity in their statements.

\section{Data Analysis}

Transcripts were coded into meaning units such as "a place to get going in the world," and "see improvement in others." Using an open coding method (Strauss \& Corbin, 1990), we refined the codes 
VOLUNTARY PARTICIPATION IN REHABILITATION

by using constant comparison to move back and forth between the transcripts and the codes. During second level coding, we looked for general themes and re-coded the data. As a result, comments such as "always something to do," "having something to do," and "busy all the time" were grouped under activities. Some statements, such as "It feels like you're welcomed the minute you walk in the door," could be coded in multiple ways. Likewise, comments such as "feels like home," "accepting place," "safe place," and "low stress," suggested both a sense of belonging and an accepting environment and were coded on both concepts. We then examined all responses for underlying themes and concepts. Staff and member responses were also compared to explore areas of concurrence, disagreement, and gaps.

Since the literature on organizational behaviour has not dealt with intentional communities such as the Clubhouse, it was difficult to frame responses relating to themes of hope, management of symptoms, and a sense of belonging within a theoretical context of climate or culture. To determine other theoretical implications, we reviewed the literature on "consumers" and "survivors" of mental illness. The recovery literature, combined with that on organizational climate, provided the most complete interpretation of the data. We categorized the following concepts: hope, incorporating (acceptance of) the illness, managing symptoms, redefining the self, meaningful activities, empowerment, control, support of others, belonging, and the physical and emotional tone of the environment (climate).

\section{Characteristics of Participants}

Member participants (64\% male and 36\% female) ranged in age from 24 to 66 and length of membership ranged from two weeks to five years. Most had been Clubhouse members for more than one but less than three years. Participants most often self-identified with diagnoses of schizophrenia, major depression, and bipolar disorder; however, phobias, obsessive-compulsive disorders, and attention deficit/hyperactivity disorders were also reported. When compared with overall membership, group participants were representative for age, gender, and diagnosis.

The seven staff members who participated ranged in age from 22 to 54, and consisted of five fulltime employees (three female, two male) and two female interns. Length of employment ranged from six months to five years. Since it takes a staff person up to six months to assimilate the organizational culture, staff longevity assured a well-informed view of the organization. In order to reduce the possibility of administrative influence, by staff consensus, the director did not join the focus group.

\section{RESULTS}

\section{Question \#1: Why Do You Come to Clubhouse and Why Do You Think Other People Come?}

Participants were prolific in response to this question, often identifying two or three issues involving activities, relationships, and a welcoming, low-stress environment. Answers to Question 1 were coded into four over-arching themes: (a) individual needs, (b) interpersonal relationships, (c) activity-oriented opportunities, and (d) the environment or climate. One member describes this as: "I wanted to come to a place where I was useful and I wanted to come to a place where I was more 
involved in what is going on. Once I came here, I found that I am getting to know people." These themes were concrete and readily attributed to specific activities. Value or attitude statements such as: "feel at home," "accepting," "opinion counts," and "positive expectations" were applicable to multiple themes. We coded these as attitudes and beliefs that reflect the organizational climate. Comments are attributed as follows: I for interviewer; $\mathrm{M}$ for member; $\mathrm{S}$ for staff. In the words of one member:

I find here that your opinion does mean something - a member having an idea is not a foreign idealike in a day program where it does not happen. Here it seems like it is fostered. (M)

The opportunity to be involved in meaningful activities of one's choice was a prominent factor. Of the activities mentioned, meaningful work that is part of daily operations (clerical, computer-based, food preparation, and clean-up) was most frequently cited. Although recreational activities were included under the umbrella of activities, they were not mentioned as often or eloquently. While people appreciated some recreation, it was the normalizing and self-affirming process of meaningful workoriented activities that was a major reason for coming. In the words of one participant:

I came to the Clubhouse because I like the idea of it being a work ordered day-gave you a purpose for getting up in the morning_-gave you the opportunity to work and socialize with other people. (M)

The importance of interpersonal relationships, the environment, and the personal qualities of individuals were frequently mentioned in all the groups themes. Most often mentioned were hope and positive expectations, dignity and respect in an atmosphere that was caring, and welcoming. Relationships were spontaneously described as supportive and not divisive. Some commented that the example of others was reciprocal, instilled hope, and led to mutually positive expectations: "affirming myself through affirming the expectations of others" (M).

These pervasive comments were conceptualized as overarching values or attitudes that captured feelings of belonging, caring, equality, empowerment, and hope. Furthermore, responses such as "my opinion counts" had layered meanings and some referred to multiple domains:

Here I find the relationships good, they are honest, you can go in and out of them-you don't need them all the time... It's just the relationship thing got me here right in the beginning-at Self Help I felt like I was "a plant in the garden," you know. They'd come and water me. (M)

One unique feature of Clubhouses is that staff and members work together as "colleagues" in the operation of the Clubhouse. By design, staffing is never sufficient to handle all tasks without member involvement, and no activity or program space is designed to be exclusively for staff or members. This egalitarian climate was widely viewed as an important positive aspect of the environment:

I really appreciate the philosophy of the Clubhouse too-members and staff working together. I don't know if there are many other organizations like this-it seems like the members and staff "melt" together. For somebody coming in I think it is hard to tell them apart. (M)

Further, it was compared to clinical and rehabilitative environments:

I was going involuntarily to a day program ... I felt very inferior there; the doctors had a big superiority complex. I didn't like that kind of environment and when I was introduced to the Clubhouse I learned in time that it was a very comforting, welcoming environment for me. 
VOLUNTARY PARTICIPATION IN REHABILITATION

\section{Question \#2: Why Do People Stop Coming to Clubhouse? What Would Make You Stop Coming?}

While the second question might appear to be the reverse of the first, it elicited a set of responses focused on the characteristics of interpersonal interactions (between members, and between staff and members) and personal characteristics of individual members. Interactions perceived as hostile led people, understandably, to avoid the Clubhouse:

As far as I am concerned our major problems walked out of the door last year and have not come back. These are people who were trouble makers and very aggressive. One person was so difficult that I had to take two weeks off from the Clubhouse just to recover. (M)

This statement also referred to the environment and the importance of "feeling safe." In the words of one member: "This is like family for a lot of people — and just like a family people can get disruptive and others can be really sensitive to that." The concept of safety was distinguished from the issue of irritating behaviour by those who may be intrusive but not threatening.

Interactions with staff where members felt misunderstood, not respected, or not treated as equals, were also deterrents to participation. It was evident that not all felt understood or appreciated by all staff. This lack of understanding is especially difficult for people whose self-confidence has already been shattered by the effects of depression, anxiety, and the sequellae of psychoses. It also highlights the importance of Clubhouse relationships as equal and collegial. The following dialogue captures this dynamic:

M1: Like staff started not being nice. If they started being bossy and stuff. I think I would leave. I like nice friendly people.

I: So it would be an attitude kind of thing.

M1: Yah

I: When you say boss...

M1: Attitude. Like better than you.

I: Now you said a couple of distinct things.

M1: OK attitude and being bossy.

M2: Or when staff makes decisions without members ... without sharing or having input from members.

This second question led to some venting of individual frustrations, such as management's lack of responsiveness to making and implementing decisions in a timely manner and the time-consuming nature of consensus-style decision-making. Lack of meaningful work was a deterrent, since these meaningful activities were important motivators. However, these comments about organizational process came from people who continued to attend and may be less important than the most prominent issue of relationships. 


\section{The "Readiness" Component}

Not everyone is ready or able to engage in the Clubhouse model of participatory rehabilitation. Individual characteristics contribute to engagement in several ways. Members with active psychotic or depressive symptoms, for example, often find it difficult to interact with others or to participate in focused activities. Thus, being "too sick" and feeling unready to participate in structured activitydescribed in terms such as having "too many symptoms," needing "to be stabilized, feeling "overwhelmed," or feeling "pressured by too many demands"-were the most frequently given explanations for people choosing not to engage in activities. Lack of desire to work and the desire to be taken care of also were cited. While it is often assumed that work-oriented rehabilitation programs are suitable for anyone recovering from a mental illness, member feedback suggests that some people are more appropriately served in a drop-in centre environment subsequent to clinical treatment.

The comment "holding tank" with respect to Self Help ${ }^{1}$ should not be understood in a totally critical sense for some people all they can to is make it there and sit around, as they are so critically ill. It's a good place for them and $\mathrm{CH}$ is not so I am glad they have that opportunity. (M)

Clubhouse readiness should also not be confused with level of functioning. Readiness speaks to the individual's acceptance of the illness and a desire to function maximally within those constraints, whether these are physical limitations, the need for a low stress environment, or the need for a less intense pace of activities. Level of functioning, on the other hand, refers to an individual's performance abilities in various domains (physical, intellectual, and emotional) as compared to a normative group. While Clubhouse welcomes persons with varying abilities, it must recognize three important elements of readiness: (a) acceptance of illness, (b) desire to be engaged in meaningful activities, and (c) recognition of the importance of relationships with others.

With regard to non-participation in Clubhouse activities, all groups acknowledged that symptoms, whether depressive or psychotic, would lead people to "stay in bed" while auditory hallucinations could convince some individuals that they are unwelcome. There was further agreement across all groups that members leave the Clubhouse because they get well, become employed, or relocate. However, in identifying the negative contributions to non-participation, members and staff were sharply contrasted in their focus on environmental rather than personal characteristics. Staff participants were more apt to ascribe attendance to individual characteristics of readiness; member participants, on the other hand, were more likely to identify negative factors in the organization's climate and stressful interpersonal relations. Most frequently, they cited conflict with another member or with staff, although they also acknowledged that lack of staff understanding of mental illness, too much emphasis on work, and lack of individual recognition or acknowledgement could, cumulatively, lead a person to "drop out" of a Clubhouse program.

When staff and members responses were compared, repeated themes were noted. Both acknowledged that, for members to become engaged in Clubhouse programs, there was a need for both some stability of symptoms and a motivation to be active. Although all mentioned the importance of the work-ordered day, they also pointed out that excessive emphasis on maintenance activities could lead to neglect of the interpersonal interactions that are primary. Staff participants voiced less awareness than members of the many aspects of environment that are important. Specifically, members articu- 
VOLUNTARY PARTICIPATION IN REHABILITATION

lated the need for an environment that was safe, calm, conflict-free, welcoming, and like home-a place where people were friendly and were treated with respect, where everyone's opinion counted, and where the atmosphere was co-operative as opposed to competitive. Finally, members were acutely sensitive to the delicate balance between staff understanding the dynamics of various forms of mental illness and psychotropic medications (which was desired) and not taking a clinical (i.e., treatment) stance in their relationships.

All member groups highlighted the importance of environmental characteristics which connote acceptance, warmth, and low stress. They advocated for a climate that was normalizing, perceived as a place of business, and encouraging of a work-ordered day — which included people dressing well, a smoke free environment, zero drug and alcohol tolerance, the availability of low-priced and attractive meals, cleanliness, and attractiveness. Such characteristics, they stressed, provide a positive environment which enhances and values the qualities that they saw in others and believed were also a reflection of themselves.

\section{DISCUSSION}

\section{Lessons Learned: Clubhouse as a Recovery Environment}

Early rounds of data analysis generated themes with individual and interpersonal components and with organizational climate content. A meaningful, cohesive explanation emerged from concepts of recovery and organizational climate. Recovery elements have been summarized as: (a) incorporating the illness (acceptance), (b) managing symptoms, (c) renewing hope and commitment, (d) redefining the self, (e) assuming control, (f) becoming empowered, (g) overcoming stigma, (h) being involved with meaningful activities, and (i) being supportive of others (Davidson, O'Connell, Tondora, \& Lawless, 2005). These elements are primarily characteristics of the individual. Since people do not recover in a vacuum, it is the characteristics of the organization's environment (climate) - its values, attitudes, and beliefs - that define a recovery environment. Participants told us that this climate extends beyond the provision of activities and services to include over-arching values of empowerment, collegial respect, hope, and positive expectations.

We found considerable congruence between the recovery literature and our findings. The major themes echoed basic elements: (a) individual, interpersonal, and environmental opportunities infused with values of hope, empowerment, and respect for independence and individuality; (b) the importance of relationships; and (c) the support for and from others. These also reflect the issues of trust, hope, and role modelling mentioned by Norman (2002). The group feedback contextualized the importance of these elements by suggesting that, for most people, the egalitarian, caring, and respectful relationships with staff and members alike are a foremost and critical component of a recovery environment. Essential elements of such relationships are restorative (i.e., healing, calming, and helpful in avoiding hospitalization). This emphasis on relationships coupled with a climate that was frequently described as "Clubhouse is like family" and that "this feels like home" were stark reminders that overcoming the isolation and loneliness of mental illness in a positive milieu is a fundamental step on the recovery road. 
Previous studies of Clubhouse functioning have alluded to some of these elements. Norman (2006) spoke about the importance of work for members. She described work as establishing the environment and allowing for relationships. In contrast, our findings suggest that the organizational climate is foundational to establishing relationships and allowing purposeful activities.

The Clubhouse environment provides four domains for recovery-individual, interpersonal, activity-oriented, and environmental (climate)—upon which are superimposed overarching values of acceptance without stigma, empowerment, self-determination, egalitarian relationships, independence, interdependence, dignity, respect, hope, and positive expectations. Some aspects of this conceptual model are implicitly captured in Clubhouse standards that specify operating procedures. However, the over-arching values which provide the fundamental framework for a successful recovery environment are not directly addressed. It is this value framework that may also be conceptualized as the Clubhouse culture.

The culture of an organization is ordered around the values, attitudes, and beliefs that its members hold in common, and is shared through traditions, rituals, symbols, and artefacts that identify the organization (Schein, 1996). Investigators have linked organizational culture with performance in key areas of productivity (Kotter \& Heskett, 1992) and this causal relationship has been explored in health services (Dyer, 1994; Flood, 1994; Grusky, 1995; Klingle, Burgoon, Walid, \& Callister, 1995). Elements of organizational culture have been linked to satisfaction with service (Waegemakers Schiff, 2001). Onken and colleagues (Onken, Dumont, Ridgeway, Dornan, \& Ralph, 2002) note that "little attention has been paid to the measurement of the environment facilitating recovery to date" (p. 9).

Previous efforts to describe Clubhouse culture have been limited and non-specific. Both Anderson (1998) and Jackson (2001) wrote of its culture but failed to provide descriptors or to link culture to performance such as member retention. The work of Norman (2006) supports our findings that work is an important motivator in a Clubhouse. However, she considers the environment as a thematic subculture, defined within an anthropological framework, rather than as one embedded in organizational theory. This study identified major values, attitudes, and beliefs of Clubhouse culture and their primacy in establishing an organization to which people will come and stay. Our conclusions on the importance of the environment as a critical element also concur with Glisson's work in children's mental health organizations (Glisson \& James, 2002). Based on the results reported here, we recommend a quantitative study that incorporates elements of the Clubhouse culture and environment.

\section{Considerations of the Study}

Any investigation that relies on participants in a focus group cannot be assured of inclusivity of all viewpoints. In this study, even though some inactive participants did give voice to their previous experiences, members who have found work or left for other activities were not represented. Further, those members who participated in the focus groups were more likely to be regular attendees. People who are reluctant to participate in group discussions are also missing from this study. Efforts were made to encourage former members to participate; however, those who did clearly may not have represented the full range of potential issues. Although every effort was made to provide a neutral and 
VOLUNTARY PARTICIPATION IN REHABILITATION

confidential environment for the focus groups, the fact that groups were held at the Clubhouse might have made some participants hesitant to epress their views. Finally, there is no way to ascertain the extent to which the focus groups represented the entire membership.

\section{Implications for Practice}

Clubhouses are intentional communities that stress the importance of interpersonal relationships within an environment that provides structure while instilling values of positive expectations, hope, and a sense of empowerment. Staff members who work within this organizational context must be comfortable with the egalitarian aspect of these relationships and be willing to let the "clinical expert" remain a silent observer of ongoing interactions. They must have expertise in understanding the unique challenges faced by someone who has been mentally ill, or who is still experiencing symptoms of the illness, coupled with the recognition that clinical understanding is not the equivalent of clinical intervention. Because of the primary importance of relationships within the Clubhouse context, staff should be cognizant of the different and shifting emotional and mental issues that members experience, without stepping into a formal therapy role. This implies a skilful balance of understanding and intervention that is posited in egalitarian, empowering relationships. For professionals who have long been trained in models of care that assume a professional expertise and thus a subtle level of superiority, an intervention model that equalizes relationships presents challenges in re-definition of the helping relationship. Equally important is the recognition that individual relationships are insufficient, and the organizational context has a major influence on members and staff.

This study was a preliminary investigation into membership retention. It provided some important lessons for the ongoing successful operation of Clubhouses. Organizational factors that influence interpersonal relationships, the opportunities for meaningful activities, and the organizational climate are critical influences in member retention and thus in organizational performance. Programs that embrace a Clubhouse philosophy and intend to provide, by consumer definition, an optimal recovery environment need, in design, implementation, and monitoring, to emphasize relationships, organizational climate, and activities.

\section{NOTE}

1. Self-Help is a drop-in centre geographically near the Clubhouse. Preference for the Clubhouse environment is validated with this easily available option.

\section{RÉSUMÉ}

Les Clubhouses, en tant que communautés intentionnelles, peuvent êtres d'excellents baromètres d'environnements de récupération et de réadaptation pour des personnes souffrant de troubles mentaux. Afin de comprendre pourquoi des gens s'affilient avec un Clubhouse tandis que d'autres s'en délaissent, 5 focus groups, composés de membres et d'employés et employées, ont exploré des questions autour de la rétention des membres. Les réponses touchaient 4 domaines: personnel, interpersonnel, la structure et l'environnement organisationnel. L'acceptance sans préjugé, le pouvoir d'agir, l'autodétermination, les relations égalitaires, l'indépendance, l'interdépendance, la dignité, le respect, 
l'espoir et les attentes positives sont des valeurs qui furent tissées intégralement dans les discussions. Ces valeurs correspondent aux éléments qui favorisent la réadaptation. La présence ou l'absence de ces éléments était invoquée pour justifier soit la participation du membre, soit son éloignement de l'organisation. Les conclusions globales des groupes suggèrent que l'environnement organisationnel ainsi que les valeurs orientés vers la réadaptation sont des facteurs importants pour déterminer la participation aux programmes volontaires.

\section{REFERENCES}

Anderson, J. (1998). We are not alone: Fountain House and the development of a Clubhouse culture. New York: Fountain House.

Angers, M. (1992). Activities of daily living in the Clubhouse: You can't vacuum in a vacuum. Psychosocial Rehabilitation Journal, 16(2), 117-123.

Aquilla, R., Santos, G., Malamud, T., \& McCorory, D. (1999). The rehabilitation alliance in practice: The Clubhouse connection. Psychiatric Rehabilitation Journal, 23(1), 19-23.

Beard, J.H., Malamud, T.J., \& Rossman, E. (1978). Psychiatric rehabilitation and long-term hospitalization rates. Schizophrenia Bulliten, 4(3), 622-635.

Beard, J.H., Propst, R.N., \& Malamud, T.J. (1982). Fountain House model of psychosocial rehabilitation. Psychosocial Rehabilitation Journal, 5(1), 47-53.

Belgrave, L., Zablotsky, D., \& Guadagno, M. (2002). How do we talk to each other? Writing qualitative research for qualitative writers. Qualitative Health Research, 12(10), 1427-1439.

Boll, J. (1995). Member roles in program evaluation: A case study from a psychosocial Clubhouse. Psychiatric Rehabilitation Journal, 19(1), 79-82.

Bond, G.R., Drake, R.E., Becker, D.R., \& Mueser, K.T. (1999). Effectiveness of psychiatric rehabilitation approaches for employment of people with severe mental illness. Journal of Disability Policy Studies, 10(1), $18-52$.

Boyd, A.S. (1997). The relationship between the level of personal empowerment and quality of life among psychosocial Clubhouse members and consumer-operated drop-in center participants. Virginia Commonwealth U. Dissertation Abstracts International Section A: Humanities and Social Sciences. Vol 58(3-A), Sep 1997, pp. 1089.

Coolidge, J., Wright, M., \& DiSanto, D. (1995). Quyana House: A Clubhouse for Alaska Natives/American Indians. Journal of the Alliance for the Mentally Ill, 6(3), 64-65.

Crowther, R., Marshall, M., Bond, G., \& Huxley, P. (2002). Helping people with severe mental illness to obtain work: Systemic review. Community Mental Health Journal, 38(3), 271-271.

Davidson, L., O'Connell, M., Tondora, J., \& Lawless, M. (2005). Recovery in serious mental illness: A new wine or just a new bottle? Professional Psychology: Research and Practice, 36(5), 480-487.

Donnell, C. (2001). The Clubhouse model in Michigan: A preliminary examination of individual and organizational characteristics associated with employment outcomes. Michigan State University.

Dorio, J., Guitar, A., Solheim, L., Dvorkin, C., \& Marine, S. (2002). Differences in job retention in a supported employment program: Chinook Clubhouse. Psychiatric Rehabilitation Journal, 25(3), 289-298.

Dorio, J., \& Marine, S. (2004). Tying it all together-The PASS to success: A comprehensive look at promoting job retention for workers with psychiatric disabilities in a supported employment program. Psychiatric Rehabilitation Journal, 28(1), 32-39.

Dyer, R.L. (1994). CMHC survival: Adapting to the community mission. Administration in Policy and Mental Health, 21(4), 309-317.

Everett, B., Adams, B., Johnson, J., Kurzawa, G., Quigley, M., Wright, M., et al. (2003). Recovery rediscovered: Implications for mental health policy in Canada. Canadian Mental Health Association. Retrieved June 6, 2005 from www.cmha.ca/english/research/images/Recovery_Policy_Paper_National.pdf+onken+\%2B+ mental+health+recovery.

Flood, A.B. (1994). The impact of organizational and managerial factors on the quality of care in health care organizations. Medical Care Review, 51(4), 381-428. 


\section{VOLUNTARY PARTICIPATION IN REHABILITATION}

Glasser, B.G. (1992). Emergence versus forcing: Basics of grounded theory analysis. Mill Valley, CA: The Sociology Press.

Glickman, M. (1992). Organizing for Clubhouses: The Massachusetts success story. Psychosocial Rehabilitation Journal, 16(2), 55-59.

Glisson, C., \& James, L. (2002). The cross-level effects of culture and climate in human service teams. Journal of Organizational Behavior, 23(6), 767-794.

Grusky, O. (1995). The organization and effectiveness of community mental health systems. Administration and Policy in Mental Health, 22(4), 361-388.

Jackson, R.L. (2001). The Clubhouse model empowering applications of theory to generalist practice. Belmont, CA: Wadsworth/Thompson Learning.

Johnsen, M., McKay, C., Corcoran, J., \& Lidz, C. (2002). Characteristics of Clubhouses across the World: Findings from the International Survey of Clubhouses 2000. 1-26. Paper presented at the International Seminar on Clubhouse Development, Minneapolis, MN.

Klingle, R.S., Burgoon, M., Walid, A., \& Callister, M. (1995). Rethinking how to measure organizational culture in the hospital setting. Evaluation and the Health Professions, 18(2), 166-186.

Kotter, J.P., \& Heskett, J.L. (1992). Corporate culture and performance. New York: The Free Press.

Landis, J. (1999). Estimating net effects and costs of service options for persons with serious mental illness. Psychiatric Services, 50(6), 735-738.

Leff, S., Cook, J., Gold, P., Toprac, M., Blyler, C., Goldberg, R., et al. (2005). Effects of job development and job support on competitive employment of persons with severe mental illness. Psychiatric Services, 56(10), 1237-1244.

Macias, C. (2001). Final Report: Massachusetts Employment Intervention Demonstration Project. “An Experimental Comparison of PACT and Clubhouse.” Retrieved June 12, 2008, from http://files.fountainhouse.org/ samhsa_final.pdf.

Macias, C., Barriera, P., Alden, M., \& Boyd, A.S. (2001). The ICCD benchmarks for Clubhouses: A practical approach to quality improvement in psychiatric rehabilitation. Psychiatric Services, 52(2), 2007-2213.

Macias, C., DeCarlo, L.T., Wang, Q., Frey, J., \& Barreira, P. (2001). Work interest as predictor of competitive employment: Policy implications for psychiatric rehabilitation. Administration and Policy in Mental Health, 28(4), 279-297.

Macias, C., Jackson, R.L., Schroeder, C., \& Wang, Q. (1999). What is a Clubhouse? Report of the 1996 ICCD survey of USA Clubhouses. Community Mental Health Journal, 35(2), 181-190.

Norman, C. (2006). The Fountain House movement: An alternative rehabilitation model for people with mental health problems, members' descriptions of what works. Scandinavian Journal of Caring Sciences, 2006(20), 2.

Oliver, J., Huxley, P., Bridges, K., \& Mohamad, H. (1996). Quality of life and mental health services. Florence, KY: Taylor \& Frances/Routledge.

Onken, S., Dumont, J., Ridgeway, P., Dornan, D., \& Ralph, R. (2002). Mental health recovery: What helps and what hinders? A National Research Project for the Development of Recovery Facilitating System Performance Indicators. National Association of State Mental Health Program Directors (NASMHPD) and the National Technical Assistance Center for State Mental Health Planning (NTAC). Retrieved June 15, 2005, from http://www.dmh.cahwnet.gov/mhsa/docs/meeting/05may04/Recovery\%20Indicators.pdf.

Resnick, S., Rosenheck, R., \& Lehman, A. (2004). An exploratory analysis of correlates of recovery. Psychiatric Services 55(5), 540-547.

Rosenfeld, S., \& Neese-Todd, S. (1993). Elements of a psychosocial Clubhouse program associated with a satisfying quality of life. Hospital and community Psychiatry, 44(1), 76-78.

Schein, E.H. (1996). Culture: The missing concept in organization studies. Administrative Science Quarterly, $41(2), 229-243$.

Strauss, A.L., \& Corbin, J. (1990). Basics of Qualitative Research: Grounded Theory Procedures and Techniques. Newbury Park, CA: Sage.

Waegemakers Schiff, J. (2001). The measurement of organizational culture in mental health clinics and the correlation of cultural dimensions with satisfaction with service. Dissertation Abstracts International Section A: Humanities and Social Sciences. Vol 61(9-A), Apr 2001, pp. 3774. Columbia University, New York. 


\section{CANADIAN JOURNAL OF COMMUNITY MENTAL HEALTH}

Warner, R., Huxley, P., \& Berg, T. (1999). An evaluation of the impact of Clubhouse membership on quality of life and treatment utilization. International Journal of Social Psychiatry, 45(4), 310-320.

Yau, E.F., Chan, C.H., Chan, A.S., \& Chui, B.K. (2005). Changes in psychosocial and work-related characteristics among Clubhouse members: A preliminary report. Work, 24(4), 287-298.

Yildiz, M., Tural, Ü, Kurdoğlu, S., \& Emin Önder, M. (2003). An experience of a Clubhouse run by families and volunteers for schizophrenia rehabilitation. Turkish Journal of Psychiatry, 14(4), 281-287. 